Revista Universo Contábil, ISSN 1809-3337

FURB, v. 5, n.3, p. 24-42, jul./set., 2009

doi:10.4270/ruc. 2009320

Disponível em www.furb.br/universocontabil

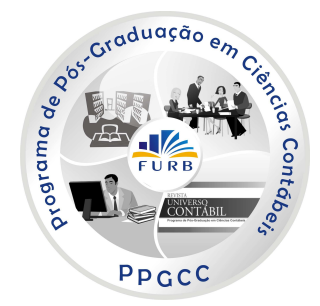

\title{
EFEITOS NO RETORNO E NA LIQUIDEZ MÉDIA DAS AÇÕES DE EMPRESAS QUE EMITIRAM ADRS NA NYSE E DAS QUE ADERIRAM AO NOVO MERCADO'
}

\section{EFFECTS ON RETURN AND ON AVERAGE LIQUIDITY OF THE SHARES OF THE COMPANIES THAT ISSUED ADRS IN NYSE AND THE ONES THAT ADHERED TO THE NEW MARKET}

\author{
Lóren Cristina Neves \\ Bacharel em Ciências Contábeis pela Universidade Federal de Uberlândia \\ Endereço: Av João Naves de Ávila, 2121 - Campus Santa Mônica - Bloco F \\ CEP: 38408-100 - Uberlândia/ MG - Brasil \\ E-mail: lorencn@hotmail.com \\ Telefone: (34) 3239-4176 \\ Sirlei Lemes \\ Doutorado em Controladoria e Contabilidade pela FEA/USP \\ Professora do Programa de Pós-Graduação em Administração da \\ Universidade Federal de Uberlândia \\ Endereço: Av João Naves de Ávila, 2121 - Campus Santa Mônica - Bloco F \\ CEP: 38408-100 - Uberlândia/ MG - Brasil \\ E-mail: sirlemes@uol.com.br \\ Telefone: (34) 3239-4176
}

\section{RESUMO}

Os efeitos no retorno e na liquidez média das ações, diante das duas situações: quando empresas aderem e atendem aos requisitos do Novo Mercado e quando empresas emitem $A D R s$ e, por conseguinte, atendem aos requisitos da Sarbanes-Oxley, são avaliados neste trabalho por meio do método de Estudo de Eventos. Os eventos considerados foram as datas de adesão ao Novo Mercado e as datas de depósito do formulário 20-F na $S E C$, após o prazo limite de adequação das empresas estrangeira à Lei. O teste-t de Student, em um nível de significância de 5\%, foi utilizado para os índices de desempenho dos retornos anormais e da liquidez média, no período de $(-15)$ a $(+15)$ dias ao redor das datas dos eventos. Os resultados evidenciam que não existem diferenças estatísticas que permitam afirmar que há

\footnotetext{
Artigo recebido em 23.07.2008. Revisado por pares em 03.11.2008. Reformulado em 17.12.2008. Recomendado em 28.01.2009 por Ilse Maria Beuren (Editora). Publicado em 30.09.2009. Organização responsável pelo periódico: FURB.
} 
valorização do retorno das empresas que emitem $A D R s$ na $N Y S E$, em relação às empresas que estão listadas no Novo Mercado. Também não foram identificadas diferenças estatísticas no comportamento da liquidez média das ações dessas empresas. No entanto são apontadas diferenças estatísticas no comportamento da liquidez das ações preferenciais em relação às ações ordinárias das empresas que emitem ADRs na NYSE.

Palavras-chave: Novo Mercado. Lei Sarbanes-Oxley. ADRs. Estudo de eventos.

\section{ABSTRACT}

The effects on return and on average liquidity of the shares, in the two situations (when some companies adhere and meet the requirements of New Market and when some companies issue ADRs, and so meet the Sarbanes-Oxley requirements) are assessed in this research by using the Event Study methodology. The events considerate were the adherence dates to the New Market and the deposit dates of the form 20-F in SEC, after the adjustments due date to meet the law. The test-t of Student, at a significance level of 5\%, was applied to the performance indexes of the abnormal return and average liquidity, in the period of $(-15)$ to $(+15)$ days around the events dates. The results show that there is no statistic difference that allows affirming that there is a return increase in companies that issue ADRs in the NYSE. Also, statistic differences were not identified in the behavior of the average liquidity of the shares in these companies. However, there are statistic differences in the behavior of the average liquidity of the preferential shares against the ordinary shares in the companies that issue ADRs in the NYSE.

Keywords: New Market. Sarbanes-Oxley Law. ADRs. Event study.

\section{INTRODUÇÃO}

Devido à abrangência do mercado acionário e a possibilidade de ampliar as fontes de captação de recursos financeiros a custos menores, algumas empresas brasileiras buscam captar recursos financeiras de países desenvolvidos por meio da emissão de títulos negociados fora do Brasil, denominados DRs (Depositary Recepts). Os títulos negociados nos Estados Unidos são definidos como ADR (American Depositary Recepts).

Após alguns escândalos financeiros, foi aprovada a Sarbanes-Oxley (SOX), que é uma lei que estabelece regras de transparência às empresas com ações nos Estados Unidos. Ela determina, inclusive, o envolvimento individual dos responsáveis pelas informações contidas nas demonstrações financeiras.

No cenário nacional, o Novo Mercado é um segmento no qual as empresas que possuem ações na Bolsa de Valores de São Paulo (BOVESPA) podem se comprometer a adotar práticas de Governança Corporativa e disclosure adicionais em relação aos exigidos pela legislação. O principal diferencial do Novo Mercado é a proibição referente à emissão de ações preferenciais.

De acordo com De Paula (2003), é conveniente aglutinar os temas relacionados com a governança corporativa em três dimensões principais: estrutura de propriedade, práticas e políticas públicas. O Novo Mercado e a $S O X$, apesar de se enquadrarem mais em uma determinada dimensão da governança corporativa, o primeiro está mais direcionado à dimensão - estrutura de propriedade, e a segunda está mais próxima da terceira dimensão políticas públicas. Ambos estão permeados por práticas de governança, dentre elas, a transparência e a integridade das informações disponibilizadas ao mercado acionário.

Os investidores, com mais informações, estariam mais seguros para investir, o que, portanto, aumentaria a demanda por ações das empresas que adotam práticas de governança 
adicionais, ocasionando um aumento da liquidez das suas ações. Segundo Martins, Silva e Nardi (2006), entre os diversos benefícios apontados pela BOVESPA, para as empresas de capital aberto que aderirem aos níveis diferenciados de governança, encontra-se o aumento de liquidez. Assim, este trabalho relata um estudo cujo objetivo principal foi investigar quais são os efeitos no retorno e na liquidez média das ações brasileiras diante das duas situações: quando empresas aderem e atendem aos requisitos do Novo Mercado e quando empresas emitem $A D R$ e, por conseguinte, atendem aos requisitos da Sarbanes-Oxley. Cabe ressaltar que empresas que aderem ao Novo Mercado podem não ser as mesmas que emitem $A D R$.

O trabalho está estruturado da seguinte forma: a introdução, que aborda o tema, a sua relevância e os objetivos do trabalho. A segunda seção é focada no referencial teórico, e menciona assuntos relacionados ao problema de pesquisa, a saber: mercado de ações no Brasil; governança corporativa; os American Depositary Receipts (ADRs); breve apresentação da Lei Sarbanes-Oxley; e os efeitos do mercado eficiente. Na terceira seção, a metodologia de estudo é detalhada para facilitar o entendimento das ferramentas estatísticas utilizadas. A quarta seção é reservada para a apresentação dos resultados encontrados. Na quinta seção, são feitas as considerações finais do trabalho.

\subsection{Problema de pesquisa e hipóteses}

A SOX exige que o presidente e o diretor financeiro da companhia divulguem um relatório sobre a efetividade dos controles internos e da elaboração das demonstrações financeiras, juntamente com os relatórios anuais. Tal exigência não é prevista na legislação brasileira.

Ao considerar que o envolvimento individual dos gestores nas informações prestadas tende a inibir a manipulação dos resultados e as ações fraudulentas na geração das informações e, logicamente, amplia a credibilidade do mercado, a hipótese $\mathrm{H}_{0}$ a ser testada é:

$\mathrm{H}_{0}$ : $\mathrm{O}$ mercado de ações brasileiro reage positivamente, quando as empresas emitem $A D R s$ e, conseqüentemente, atendem aos requisitos da Sarbanes-Oxley comparativamente ao Novo Mercado.

Ao levar em conta que as empresas, quando disponibilizam mais informações, tendem a aumentar a liquidez de suas ações, já que há uma redução da assimetria de informações entre a empresa e os investidores. Isso ocorre de forma espontânea para as empresas que aderem ao Novo Mercado, a hipótese $\mathrm{H}_{0}$ a ser testada é:

$\mathrm{H}_{0}$ : As empresas, quando aderem ao Novo Mercado, tornam-se mais líquidas que as empresas ao atendem aos requisitos da $S O X$.

Tendo em vista que o mercado pode reagir de diversas maneiras diante das informações publicadas, o presente estudo busca responder à seguinte questão: Quais os impactos no preço e na liquidez das ações das empresas brasileiras que atenderam aos requisitos da Sarbanes-Oxley e daquelas que aderiram ao Novo Mercado?

Mediante a restrição imposta às empresas que aderem ao Novo Mercado quanto à proibição de emissão de ações preferenciais, para responder ao problema de pesquisa, serão consideradas somente as ações ordinárias das empresas listadas na BOVESPA que aderiram ao Novo Mercado e das que emitem ADRs.

\section{GOVERNANÇA CORPORATIVA E OS MECANISMOS LEGAIS}

O tema Governança Corporativa abrange uma série de conceituações, visto que envolve diversas áreas da organização, tais como: financeira, jurídica, relacionamento com investidores, planejamento estratégico, dentre outros.

Para Shleifer e Vishny (1996), a Governança Corporativa assegura, aos fornecedores de recursos financeiros, meios para que as empresas apresentem retorno aos seus 
investimentos. De forma semelhante, o IBGC (2004) define Governança Corporativa como o sistema que dirige e monitora as sociedades, e as suas boas práticas têm a finalidade de ampliar o valor da sociedade, facilitar o acesso ao capital e contribuir para a sua perenidade. No entanto, Shleifer e Viskny e IBGC enfatizam os direitos de retornos aos investidores e os sistemas de relações entre os acionistas, os conselhos de administração e a direção executiva das empresas.

De acordo com Hitt, Irland e Hoskisson (2001), o sistema de governo e estruturas de poder que abrangem a gestão e o controle das organizações disciplinam a relação das empresas com as demais partes interessadas. Os autores supracitados abordam que o foco da Governança Corporativa é a definição de uma estrutura de governo que maximize o retorno aos acionistas e os benefícios almejados pelos executivos. Neste sentido, a governança corporativa envolve a estratégia das corporações, a geração de valor e a aplicação de recursos. Para esses autores, a governança corporativa nasceu do divórcio entre a propriedade e a gestão das empresas, o que representa um reflexo da experiência anglo-saxã.

O Relatório Cadbury (1992) adota a mesma linha: a governança corporativa é o sistema de poder que rege os mecanismos pelos quais as empresas são dirigidas. O Relatório foi publicado, em julho de 1992, pela London Stock Exchange (Bolsa de Valores de Londres) e possui um número expressivo de códigos de boas práticas de governança que impactaram o mercado europeu.

Os sistemas de valores e padrões de comportamento, considerando que os sistemas de valores é que regem as corporações em suas relações internas e externas, são descritos por Claessens e Fan (1996 apud ANDRADE; ROSSETTI, 2004) como se a governança corporativa expusesse a respeito dos padrões de comportamento adotados pelas empresas para ampliar seu valor e dirimir os relacionamentos com as partes interessadas, com base nos princípios éticos aplicados à gestão do negócio.

Para Williamson (1996), a governança corporativa trata da justiça, da transparência e da responsabilidade das empresas com relação ao negócio e à sociedade. Os valores que sustentam a boa Governança são: senso de justiça, que respeita os direitos dos minoritários tanto na distribuição de riqueza quanto na presença em assembléias; a transparência das informações que impactam o negócio; a prestação de contas de acordo com os princípios contábeis e em conformidade com o cumprimento das normas reguladoras.

Do exposto depreende-se que os conceitos de governança corporativa são diversificados. Neste estudo, a governança corporativa envolve a seguinte delimitação: a governança corporativa envolve os meios pelos quais se busca atender aos diversos grupos de interesse, e em que os agentes implicados almejam segurança do retorno e da liquidez de seus investimentos. As boas práticas de gestão estão relacionadas à confiabilidade e à responsabilidade que os investidores depositam nos gestores para a aplicação dos recursos que lhes foram confiados e na transparência das informações de seus resultados.

Os mercados acionários impuseram regras para a efetivação dos conceitos de governança corporativa, tais como os requisitos exigidos pelo Novo Mercado e pela Lei Sarbanes-Oxley. O presente estudo, conforme mencionado, investiga o comportamento do mercado brasileiro diante da divulgação das informações requeridas por tais mecanismos.

A KPMG elaborou um estudo sobre os 20-F das empresas brasileiras registradas na Securities and Exchange Comission (SEC) com o intuito de verificar o empenho, as atitudes, os investimentos e como se apresentam ao mercado as atividades referentes à governança corporativa. Dentre as 33 empresas brasileiras listadas na SEC, 21 estão listadas nos Níveis Diferenciados de Governança Corporativa da BOVESPA, sendo 4 no Novo Mercado, 3 no Nível 2 e 14 estão no Nível 1. De acordo com o estudo da KPMG (2006), os aspectos relacionados com a transparência e a prestação de contas estão dentre as grandes preocupações de conselheiros e administradores, visto que se enquadram nos fatores de 
percepção do mercado, abrangendo o negócio da empresa, o seu desempenho, os seus resultados, a sua estrutura de decisão e as práticas adotadas para mitigar riscos. Quanto mais esses assuntos são discutidos e apresentados pelas empresas, maior tem sido a sua capacidade de obter recursos financeiros e a sustentação do seu valor no mercado de capitais.

\subsection{O Mercado de Ações no Brasil}

Conforme o estudo de Vieira e Mendes (2004), entre os anos de 1976 e 1997, o número de empresas com ações negociadas na BOVESPA cresceu 41\%. Ela também aponta que as empresas diversificaram as fontes de créditos e tornaram-se mais alavancadas.

Ainda de acordo com o abordado por Vieira e Mendes (2004), na década de 1990, o processo de privatização juntamente com a intensificação e diversificação do portfólio dos investidores internacionais tornaram o mercado brasileiro acessível ao mercado mundial, o que se refletiu em crescimento dos valores e volumes de ações negociadas. No entanto esse fato não significou desenvolvimento do mercado de ações brasileiro, porque o processo foi restrito e concentrado em algumas empresas.

No Brasil, a concentração de ações com direito a voto é característica das empresas de capital aberto. De acordo com Leal e Valadares (2002), o maior acionista detém, em média, $58 \%$ das ações ordinárias, e os três maiores acionistas juntos possuem $78 \%$ das ações. Mônaco (2000) menciona que os acionistas controladores possuem, em média, $88 \%$ das ações com direito a voto. Logo, o conflito de agência ocorre entre majoritários e minoritários.

Para Berglof e Claessens (2004), o país, com um sistema judiciário adequado, capaz de fazer cumprir as regras e leis estabelecidas, juntamente com um sistema legal eficiente, terá melhor desempenho financeiro. Países de fraco funcionamento e inadequado sistema de leis possuem empresas com governança corporativa fraca ou mesmo deficitária.

Em linha com a afirmação dos autores acima, Pinheiro (2003) esclarece que as deficiências do sistema judiciário brasileiro desestimulam a atividade econômica do país. Apesar do número reduzido de empresas de capital aberto, o mercado acionário mundial exige das empresas mais transparência nas informações disponibilizadas e nos procedimentos de controles adotados, o que reforça a importância do tema governança corporativa. $\mathrm{O}$ crescimento dos investimentos estrangeiros de portfólio, em países em desenvolvimento, torna-se um estímulo para as mudanças nas práticas de governança adotadas.

Camargos e Barbosa (2006) mencionam outros trabalhos realizados a respeito do impacto da adesão ao Novo Mercado e aos Níveis Diferenciados da BOVESPA, como forma de abordar o comportamento do mercado de ações brasileiro. Outros autores afirmam que apesar de muitos dos resultados dos trabalhos serem inconclusivos, grande parte deles (exceto Carvalho, 2003) sinalizam que a adesão não causou o impacto esperado no comportamento das ações, no mercado e no retorno ao acionista.

\subsection{Títulos Transfronteiriços: ADR - American Depositary Receipts}

O governo brasileiro, por meio do Anexo V da Resolução CVM no 1.289 de março de 1987, com redação aprovada pela Resolução $\mathrm{n}^{\circ} 1.927$, de 15 de julho de 1992 , permitiu as empresas de capital aberto negociar suas ações em mercados primários e secundários de economias que possuam mercados de capitais mais líquidos e eficientes. Essa medida visou alavancar o mercado de capitais brasileiro.

Segundo Camargos (2003), a insuficiência de fontes de financiamento de longo prazo é um fator que leva as empresas brasileiras a emitir $D R s$ e, de forma mais expressiva, os $A D R s$. Ainda de acordo com os autores, as empresas, ao emitir títulos transfronteiriços, almejam obter visibilidade internacional, dar maior liquidez às negociações, além de captar recursos com custos inferiores aos brasileiros. 
Andrezo e Lima (1999) esclarecem que os DRs são títulos de renda variável, negociáveis, emitidos por um banco estrangeiro (banco depositário), que representam as ações de uma empresa de um mercado diferente daquele em que o investidor está situado. As emissões de DRs são permitidas mediante pedido de registro na CVM e no Banco Central e, posteriormente, pelo estabelecimento de um relacionamento com o órgão regulador do país onde os títulos serão negociados para atender aos requisitos de transação exigidos.

Marcon (2002) aponta algumas vantagens para as empresas que emitem ADRs. Para a autora, as empresas, ao abrir o capital nas bolsas norte-americanas, ampliam o número de investidores, melhoram a imagem, aumentam a liquidez de suas ações, facilitam as fusões e aquisições internacionais e reduzem o custo de capital. "Os custos incorridos para emissão dos títulos na maioria dos casos, são inferiores aos benefícios advindos" (MARCON, 2002, p.15). Contudo outros autores buscaram analisar os efeitos da dupla listagem, ou seja, os efeitos naquelas empresas que, além do seu país de origem, emitem ações em países estrangeiros, conforme apresentado no Apêndice A deste trabalho.

\subsection{Sarbanes-Oxley}

A $S O X$ é aplicável às empresas norte-americanas e também a empresas nãoamericanas listadas no mercado de ações dos Estados Unidos, que possuam ADRs de níveis II e III negociados. Como anteriormente mencionado, dentre as regras de governança corporativa impostas por esta lei, está a certificação das demonstrações financeiras pelo $C E O$ (Cheif Executive Officer) e pelo CFO (Cheif Financial Officer). A certificação é obtida por meio de um atestado individual, assinado de próprio punho, individualizando as responsabilidades pelas informações relatadas.

A Lei estabelece regras de transparência nos atos societários e nas demonstrações financeiras, e obriga a $S E C$ a revisar os informativos divulgados ao mercado uma vez a cada três anos. Além disso, a lei amplia as penalidades associadas a fraudes.

\subsection{Eficiência de Mercado}

Segundo Camargos, Gomes e Barbosa (2003), a Hipótese da Eficiência de Mercado (HEM) constitui um dos alicerces da Moderna Teoria de Finanças. Essa hipótese pressupõe que as informações relevantes são instantaneamente inseridas nos preços dos ativos financeiros, e assim, o preço corrente de um título seria a melhor estimativa de seu preço. Não existe a possibilidade de ganhos anormais, ou seja, acima da média do mercado, nem para os investidores nem para as empresas que possuam títulos no mercado de capitais. Fama (1991) sugeriu outras classificações para os níveis de eficiência, conforme apresentado no Quadro 1.

\begin{tabular}{|c|c|c|}
\hline Forma & Características & $\begin{array}{c}\text { Nova Classificação } \\
\text { Fama (1991) }\end{array}$ \\
\hline Fraca & $\begin{array}{l}\text { O mercado incorpora completamente as informações sobre os preços } \\
\text { passados dos títulos. Isto é, retornos anormais (acima da média de mercado) } \\
\text { não poderiam ser obtidos com base nas expectativas de que os preços } \\
\text { passados são bons sinalizadores dos preços futuros. }\end{array}$ & $\begin{array}{l}\text { Previsibilidade de } \\
\text { Retornos Passados }\end{array}$ \\
\hline Semiforte & $\begin{array}{l}\text { Os preços refletem não apenas o histórico do comportamento dos preços, } \\
\text { como também toda informação pública, tais como balanços das } \\
\text { companhias, notícias na imprensa, comunicados de fatos relevantes, etc. }\end{array}$ & Estudo de Eventos \\
\hline Forte & $\begin{array}{l}\text { Além das informações mencionadas anteriomente (histórico dos preços e } \\
\text { informações públicas), os preços refletem as informações não públicas } \\
\text { (privadas). }\end{array}$ & $\begin{array}{l}\text { Testes de } \\
\text { Informação Privada }\end{array}$ \\
\hline
\end{tabular}

Quadro 1 - Níveis de eficiência e suas classificações

Fonte: Camargos e Barbosa (2003, p. 12). 
O estudo de evento, mencionado no Quadro 1, é um método que consiste, basicamente, na verificação da influência de eventos específicos na performance das empresas, por meio da investigação dos efeitos de tais eventos nos valores de mercado dos títulos das empresas (SOARES; ROSTAGNO; SOARES, 2002).

\section{METODOLOGIA}

\subsection{Estudo de Eventos}

Um estudo de eventos consiste em utilizar um modelo de geração de retorno acionário, considerado como padrão (retorno normal), o qual é tido como o retorno que o título teria, caso o evento não ocorresse (CAMARGOS; BARBOSA, 2006). Para tanto, o modelo baseiase nos retornos anormais ou extraordinários ocorridos em relação aos retornos esperados das ações em torno e na data do evento.

Paxon e Wood (1998, apud SOARES; ROSTAGNO; SOARES 2002) afirmam que o estudo de evento retrata um desenho de pesquisa empírica de ampla utilização nas áreas de Finanças e Contabilidade. Isso se deve ao fato de que, nessas áreas, se estudam os impactos dos eventos econômicos ou financeiros no comportamento do mercado de títulos.

Mackinlay (1997) e Campbell, Lo e Mackinlay (1997, apud SOARES; ROSTAGNO; SOARES 2002) indicaram os procedimentos de um estudo de evento de forma analítica, como apresentado na Figura 1.

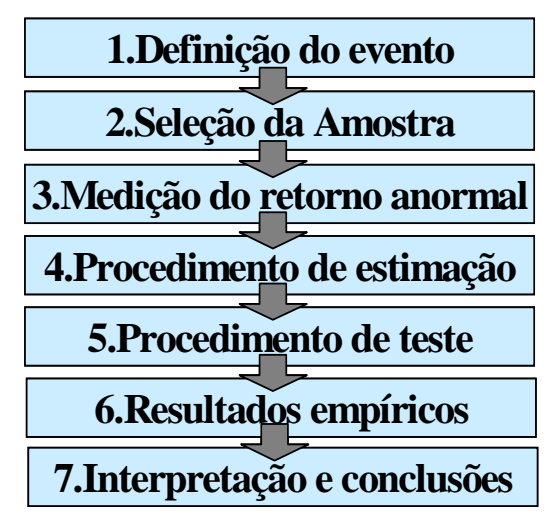

Figura 1 - Fases do Estudo de Evento

Fonte: Soares, Rostagno e Soares (2002, p. 2).

O estudo de evento é estruturado, basicamente, como segue na Figura 2.

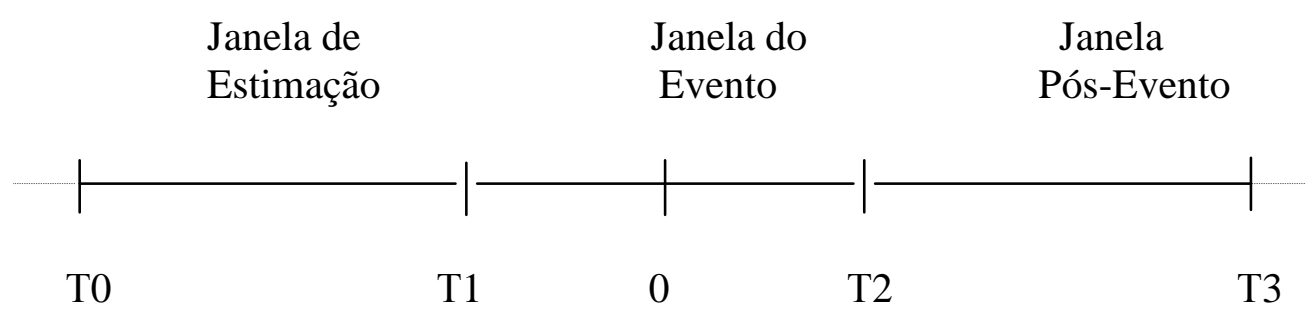

Figura 2 - Linha do tempo - Estudo de evento Fonte: MACKINLAY (1997, p. 20).

No presente estudo, duas amostras foram levantadas, sendo que para as medições do retorno e da liquidez média da amostra das empresas brasileiras que emitiram ADRs na bolsa NYSE e que atendem aos requisitos da Lei Sarbanes-Oxley. A data do evento, ou data zero, é o dia em que o formulário $20-\mathrm{F}$ foi arquivado na $S E C$. A janela do evento é o período 
compreendido entre (-15) e (+15) dias em torno da data do evento. A janela de estimação compreende noventa observações $(-105)$ a $(-16)$, ou seja, o período de noventa dias anteriores à janela do evento.

E, para a amostra das empresas brasileiras com ações listadas na BOVESPA, que aderiram e que atendem aos requisitos do Novo Mercado. A data do evento, ou data zero, é o dia da adesão ao Novo Mercado. A janela do evento é o período compreendido entre (-15) e (+15) dias em torno da data do evento. A janela de estimação compreende noventa observações (-105) a (-16), ou seja, o período de noventa dias anteriores à janela do evento

O impacto no evento é medido pelo retorno anormal ou extraordinário, e o retorno normal é definido como o retorno esperado. Este retorno é necessário para a apuração daquele, por isso, a seguir, são relatadas as formas de cálculo do retorno normal.

Soares, Rostagno e Soares (2002) abordam duas formas de cálculo para os retornos normais: a forma tradicional, que pressupõe um regime de capitalização discreta, em que se considera que as informações de mercado ocorrem em instantes distintos, causando variações discretas nos preços; a outra forma é a capitalização contínua, em que se leva em conta que as informações de mercado ocorrem a todo o momento, e as ações reagem continuamente a essas informações.

Já para o cálculo apoiado na forma de capitalização contínua, o preço do título pode ser obtido pela expressão:

$$
P_{t}=P_{t-1} e^{r}
$$

Em que:

r é a taxa de retorno.

$\mathrm{P}_{\mathrm{t}}$ é o preço da ação na data $\mathrm{t}$

$\mathrm{P}_{\mathrm{t}-1}$ é o preço da ação na data $\mathrm{t}-1$

Após os ajustes algébricos a equação pode ser definida como:

$$
r=\ln \left(\frac{P_{t}}{P_{t-1}}\right) \text { equivalente a } r=\left(\ln P_{t}-\ln P_{t-1}\right)
$$

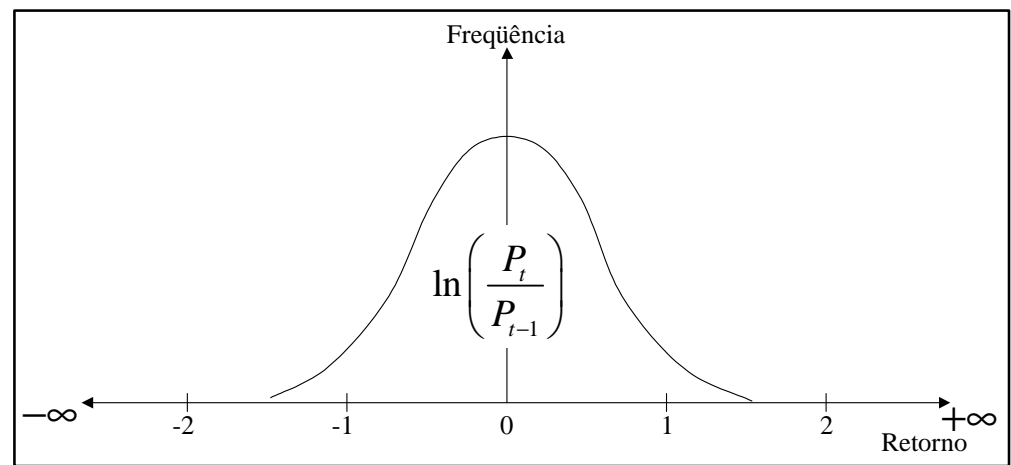

Figura 3 - Distribuição de freqüência dos retornos pela forma logarítmica Fonte: SOARES, ROSTAGNO e SOARES (2002, p.5).

A utilização da forma logarítmica resultaria em uma curva de distribuição de freqüência simétrica em relação a zero, em que a distribuição de freqüências dos retornos tende a aproximar os resultados obtidos do logaritmo natural da curva normal.

No estudo realizado por Soares, Rostagno e Soares (2002), com o objetivo de verificar a capacidade de apuração de anormalidades de diferentes modelos de cálculo do retorno 
anormal foi evidenciada maior eficácia no modelo de retorno ajustados ao risco e ao mercado. Além disso, eles constataram que este foi o modelo mais utilizado no período compreendido entre 1997 a 2001 nos Encontros da ANPAD (Associação Nacional de Pós-graduação e Pesquisa em Administração). Por isso, a escolha pela utilização desse modelo neste estudo.

$\mathrm{O}$ modelo de retornos ajustados ao risco e ao mercado algebricamente pode ser apresentado pela equação 3 a seguir:

$$
A_{i, t}=R_{i, t}-\alpha_{i}-\beta_{i} R_{m, t}
$$

Em que:

$A i, t$ é o retorno anormal da ação i no período t;

$R i, t$ designa o retorno da ação i no período t;

$R m, t$ é o retorno do portfólio de mercado no período $t$;

$\alpha i$ e $\beta i$ são valores OLS (mínimos quadrados ordinários) para o período estimado são parâmetros da regressão linear envolvendo os retornos da ação e os retornos do mercado.

Neste trabalho, optou-se pela utilização do modelo ajustado ao risco e ao mercado, considerando-se que os retornos anormais são obtidos pelos retornos individuais em relação ao mercado. Para tanto, o retorno de mercado foi mensurado pela forma logarítmica sobre o índice IBOVESPA. O beta e o intercepto, para cada ação, foram calculados na janela de estimação (-105) a (-16) dias.

Conforme os cálculos utilizados por Camargos e Barbosa (2006, p. 7), após a apuração dos retornos anormais, estes são somados (acumulados) em cada um dos dias relativos para todas as empresas que componham cada conjunto da amostra:

$$
C A R=\sum_{t=1}^{n} R A_{i t}
$$

Em que:

CAR $=$ Retorno Anormal Acumulado para a empresa i no período t;

$\mathrm{RA}=$ Retorno Anormal para determinada empresa i no período t.

$n=$ Número de empresas

O Retorno Anormal Acumulado da carteira de ações é obtido pela média aritmética dos retornos anormais das ações agrupadas. Desta forma, é possível mensurar, neste trabalho, a média dos retornos anormais das empresas que atendem aos requisitos da Sarbanes-Oxley e do conjunto de empresas que aderiram ao Novo Mercado da BOVESPA. Como apresentado a seguir, a equação 5 permite obter o índice de desempenho do retorno acumulado das ações que compõem as amostras:

$$
\text { IPRA } t=\frac{1}{N} \sum_{i=1}^{n} R A t
$$

Em que:

IPRA = Índice de Performance do Retorno Anormal Acumulado;

$\mathrm{RA}=$ Retorno Anormal para determinada empresa i no período $\mathrm{t}$ 
$\mathrm{N}=$ Número de ações por resultado (SOX ou Novo Mercado).

Soares, Rostagno e Soares (2002) apontam que a forma mais adequada de cálculo dos retornos é a logarítmica, já que apresenta uma distribuição dos retornos simétrica, ao contrário dos resultados assimétricos registrados na distribuição dos retornos, ao utilizar a forma de cálculo tradicional. A forma logarítmica apresenta distribuição de retornos mais similares à distribuição normal, que constitui uma das premissas para os testes estatísticos paramétricos.

Com o intuito de verificar se os retornos anormais acumulados entre os dois conjuntos de ações analisados são estatisticamente diferentes, é utilizado um teste paramétrico, qual seja o Teste-T de Student. Este teste foi utilizado neste trabalho devido ao objetivo de comparar as médias das variáveis entre as amostras em um nível de significância de 5\% e, sobretudo, em razão do tamanho das amostras.

\section{RESULTADOS DOS TESTES EMPÍRICOS}

A base de dados desse estudo é composta por duas amostras de empresas listadas na BOVESPA: as empresas que aderiram ao Novo Mercado; e as empresas que emitem ADR de Níveis II e III na Bolsa de Nova Iorque.

A amostra das empresas que aderiram ao Novo Mercado, até maio de 2007, era, inicialmente, composta por 63 empresas; porém, de acordo com a seção anterior, o Estudo de Evento utiliza-se da janela de estimação para o cálculo do retorno esperado. Assim, para efetuar esse cálculo, fazem-se necessários dados históricos. Os dados históricos foram obtidos para as 10 empresas que compõem a amostra das empresas listadas no Novo Mercado.

Tal necessidade deve-se ao fato de a maioria das empresas ter aderido a esse Nível Diferenciado de Governança Corporativa, no momento em que passou a emitir ações na BOVESPA, ao passo que somente 10 empresas possuíam ações na Bolsa para posterior adesão ao Novo Mercado.

Da amostra composta pelas empresas com ações na BOVESPA e que emitem ADRs Níveis II e III na NYSE, (32 empresas), foram consideradas 28 empresas que arquivaram o formulário $20-\mathrm{F}$, na $S E C$, na data necessária para compor a amostra. O período compreendido refere-se aos exercícios sociais encerrados em 31/12/2005 e arquivados na SEC em 2006.

Dentre as 28 empresas que compõem a amostra das que emitem ADRs, 22 possuem ações preferenciais; dessas, as empresas Braskem e Unibanco dispõem de diferentes classes de ações preferenciais e foram desconsideradas, totalizaando 26 eventos relacionados com as ações preferenciais observadas. As empresas que compõem as amostras estão detalhadas no Apêndice B.

\subsection{Análise dos Resultados}

No teste de comparação das médias em um nível de significância de 5\% ( $\alpha=0,05)$, se o valor calculado é menor que o valor de $\alpha$, pode-se dizer que as médias das amostras são diferentes. Em situação oposta, se o valor é maior que 5\%, as médias são iguais. A seguir, são apresentados os resultados obtidos da aplicação do teste-t.

A hipótese $\left(\mathrm{H}_{0}\right)$ é rejeitada, uma vez que não são verificadas diferenças estatisticamente significantes. Os valores do teste-t são maiores que 5\%, exceto na data (D15). Constata-se que não existem diferenças estatísticas que permitam afirmar que o mercado brasileiro valoriza mais as ações das empresas que emitam ADRs na $N Y S E$ e que, conseqüentemente, atendam aos requisitos da $S O X$ em relação às empresas que estão listadas no nível mais rígido de governança corporativa da BOVESPA, o Novo Mercado.

Assim, apesar do esforço das empresas para se adequarem e atender aos requisitos da Lei, principalmente das seções de números 302 e 404 da Lei Sarbanes Oxley, que se referem 
às certificações e divulgações para os controles internos, ainda não se pode perceber uma valorização das ações dessas empresas pelo mercado brasileiro. Também não há evidências de que o mercado brasileiro valorizou de forma distinta algum tipo de ação brasileira emitida pelas empresas com ADRs na NYSE, já que não foram encontradas diferenças estatísticas significativas entre as amostras, pois os valores de significância obtidos são maiores que 5\%.

Tais resultados podem ser interpretados como provável consequiência de dois fatores: a) o mercado acionário brasileiro não valoriza as informações adicionais do Formulário 20-F; b) os resultados encontrados podem ter sido ocasionados por se tratar de um período de adaptação às exigências a que as empresas foram submetidas, não se podendo afirmar que, após as adaptações, os resultados serão mantidos ou alterados.

Ao analisar a outra hipótese $\left(\mathrm{H}_{0}\right)$, constata-se que não há diferenças estatísticas que permitam afirmar que as empresas, quando aderem ao Novo Mercado, tornam-se mais líquidas que as empresas que atendem aos requisitos da SOX.

De acordo com os resultados apresentados, os valores da significância são inferiores a $5 \%$, o que nos possibilita afirmar que existem evidências estatísticas de que as médias das amostras são diferentes, portanto, as ações preferenciais possuem um liquidez média significativamente superior às ações ordinárias das empresas emissoras de ADRs na NYSE. Esse resultado pode ser interpretado como decorrente do fato de os investidores, nesses casos, vislumbrarem a preferência pelo retorno dos seus investimentos em vez da possibilidade de manter influência nas decisões estratégicas a serem tomadas pelos gestores das empresas, uma vez que são empresas de grande porte e de representatividade no mercado brasileiro.

Os gráficos que representam os resultados obtidos compõem o Apêndice C.

\section{CONSIDERAÇÕES FINAIS}

As amostras para testar essa hipótese corresponderam a 10 empresas listadas no Novo Mercado e 24 empresas participantes dos programas de ADRs na NYSE. Foram testadas somente as empresas com ações ordinárias, já que esta é uma premissa para as empresas listadas no Novo Mercado. Adicionalmente, foram testados os tipos de ações (ordinárias e preferenciais) das empresas com ADRs na NYSE.

As amostras contemplaram a janela do evento de (-15) a (+15) dias, que foram obtidas por meio da janela de estimação de (-105) a (-16) dias. Depois dos cálculos dos IPRAs, por meio da utilização do teste-t, verificou-se a existência de diferenças estatísticas significantes entre as amostras.

Os resultados encontrados revelaram que não existem evidências estatísticas de diferenças significativas entre as médias dos preços das amostras em um nível de 5\%. Dessa forma, a hipótese $\mathrm{H}_{0}$ é rejeitada, pois as médias dos preços apresentaram-se estatisticamente iguais. Além disso, não existem diferenças significativas entre as médias dos preços dos tipos de ações (preferenciais e ordinárias) emitidas pelas empresas com ADRs na NYSE.

A outra hipótese $\mathrm{H}_{0}$ também foi rejeitada, porque não existem evidências estatísticas que permitam afirmar que as empresas que aderem ao Novo Mercado tornam se mais líquidas que as empresas que atendem aos requisitos da SOX, ao emitir ADRs na NYSE.

No entanto observam-se diferenças estatísticas na liquidez média das ações preferenciais das empresas que emitem ADRs na NYSE no mercado brasileiro em relação à liquidez média das ações ordinárias dessas empresas. O provável fator para esse acontecimento é que os investidores, nesses casos, assumem uma postura de preferência ao retorno dos seus investimentos à possibilidade de manter influência nas decisões estratégicas a serem tomadas pelos gestores das empresas, uma vez que são empresas de grande porte e de representatividade no mercado brasileiro. Portanto, as decisões tomadas pelos gestores visam manter as características já existentes nas empresas. 
Pelo tratamento acumulado das variáveis, podem ter ocorrido outros eventos que, provavelmente, tenham afetado o comportamento das variáveis, o que é uma limitação do presente estudo, uma vez que esses efeitos externos não foram tratados estatisticamente. Os resultados encontrados também estão restritos às amostras selecionadas, logo, generalizações com relação aos resultados devem ser efetuadas com precaução.

Os seguintes fatores também podem ter afetado os resultados aqui registrados:

a) o tamanho da amostra do Novo Mercado, composta por 10 empresas;

b) as diferenças referentes aos períodos analisados - períodos de adesão ao Novo Mercado, mais diluídos, e os períodos de depósito do formulário 20-F, mais concentrados;

c) as diferenças inerentes a cada amostra - a amostra do Novo Mercado composta por empresas que buscam se consolidar no mercado, e a amostra das empresas que emitem $A D R s$ composta por empresas que já se consolidaram no mercado.

Em estudos futuros também poderá ser avaliado o comportamento do mercado brasileiro para as alterações de outras variáveis, tais como: risco, volatilidade das ações das empresas listadas no Novo Mercado e das que emitem ADRs na NYSE. A janela do estudo de evento também pode ser testada em outras amplitudes.

Espera-se que os resultados encontrados estudos contribuam para ampliar os conhecimentos a respeito do comportamento do mercado acionário brasileiro com relação às informações disponibilizadas pelas empresas.

\section{Referências}

ANDRADE, A.; ROSSETI, J. P. Governança corporativa: fundamentos, desenvolvimento e tendência. São Paulo: Atlas, 2004.

ANDRADE, M. M. A pesquisa científica: como preparar trabalhos para cursos de PósGraduação - noções práticas. São Paulo: Atlas, 1997.

ANDREZO, A. F.; LIMA, I.S. Mercado financeiro: aspectos históricos e conceituais. São Paulo: Pioneira, 1999.

BERGLOF, E.; CLAESSENS, S. Enforcement and corporate governance. World Bank Policy Research. Working Paper. n. 3409. Setembro 2004. Social Science Research Network, 2004. Disponível em: <http://papers.ssrn.com>. Acesso em: 16 jun. 2007.

CAMARGOS, M. A.; GOMES, G. D.; BARBOSA, F. V. Integração de mercados e arbitragem com títulos transfronteiriços: ADR - American Depository Receipts. Caderno de Pesquisas em Administração, São Paulo, v.10, n.2, p. 51-67, abr./jun. 2003.

CAMARGOS, M. A.; BARBOSA, F. V. Evidência empírica do impacto da adesão aos níveis de governança corporativa sobre o comportamento das ações na BOVESPA. In: ENANPAD, 30, 2006, Salvador. Anais... Rio de Janeiro: ANPAD, 2006.

CAMARGOS, M. A.; BARBOSA, F. V. Estudos de eventos: teoria e operacionalização. Caderno de Pesquisas em Administração, v. 10, n. 3, p. 1-20, jul./set. 2003.

DE PAULA, G. M. Governança corporativa no Brasil e México: estrutura patrimonial, prática e políticas públicas. Comissão Econômica para a América Latina e Caribe - CEPAL. Uberlândia, set./ 2003.

FAMA, E. F. Efficient capital markets: a review of theory and empirical work. The Journal of Finance. Chicago: American Finance Association, v. 25, n. 2, p. 383-417, maio 1970. 
FAMA, E. F.; FISCHER, L.; JENSEN, M. C.; ROLL, R. The adjustment of stock prices to new information. International Economic Review, Osaka: Universidade da Pensilvânia, v. 10, n. 1, p. 1-21, fev./ 1969.

FAMÁ, R.; RIBEIRO NETO, R. M. Uma alternativa de crescimento para o Mercado de Capitais Brasileiro - o Novo Mercado. In: SEMEAD, 5., 2001. São Paulo. Anais... São Paulo: FEA/USP, 2001.

HITT, M.A; IRELAND, R.D; HOSKISSON E.R. Strategic management competitiveness and globalization. Cincinnati: South Western College, 2001.

INSTITUTO BRASILEIRO DE GOVERNANÇA CORPORATIVA (IBGC). Disponível em: <http://www.ibgc.org.br>. Acesso em: 14 mar. 2007.

LEAL, R. P. C.; VALADARES, S. Ownership and control structure of Brazilian companies. 2000. Disponível em: <http//www.coppead.ufrj.br/ricardoleal/publicarions.html>. Acesso em: 14 mar. 2007.

MARCON, R. O custo do capital próprio das empresas brasileiras: o caso dos American Depositary Receipts (ADRs). 2002. 152 f. In: Tese (Doutorado em Engenharia de Podução) Programa de Pós-Graduação em Engenharia de Produção da Universidade Federal de Santa Catarina. Florianópolis: EPS/UFSC, 2002.

MARTINS, V. A.; SILVA, R. L. M.; NARDI, P. C. C. Governança corporativa e liquidez das ações. In: ENANPAD, 30. , 2006, Salvador. Anais... Rio de Janeiro: ANPAD, 2006.

MONACO, D. C. Estudo da composição de conselhos de administração e instrumentos de controle das sociedades por ações no Brasil. 2000. 177 f. Dissertação (Mestrado em Administração) - Faculdade de Economia, Administração e Contabilidade da Universidade de São Paulo. São Paulo: FEA/USP, 2000.

PINHEIRO, A. C. Judiciário, reforma e economia: a visão dos magistrados. Texto para discussão n. 09 IPEA. Rio de Janeiro, 2003. Disponível em: <www.ipea.gov.br〉. Acesso em: 16 jun. 2007.

SOARES, R. O.; ROSTAGNO, L. M.; SOARES, K. T. C. Estudo de evento: o método e as formas de cálculo do retorno anormal. ENANPAD, 2002. Anais Rio de Janeiro: ENANPAD, 2002. CD-ROM.

VIEIRA, S. P.; MENDES, A. G. S. T. Governança corporativa: uma análise de sua evolução e impactos no mercado de capitais brasileiro. Revista do BNDES, v. 11, n. 22, p. 103-122, dez. 2004.

WILLIAMSON, O. E. The mechanisms of governance. Oxford: Oxford University Press, 1996. 


\section{Apêndice A - Resumo dos trabalhos a respeito da dupla listagem}

\begin{tabular}{|c|c|c|}
\hline Autores & Objetivos & Resultados \\
\hline $\begin{array}{l}\text { Rodrigues, Ramos e Barbosa } \\
\text { (1999) }\end{array}$ & $\begin{array}{l}\text { Analisar por meio do "estudo de } \\
\text { eventos" as ações de empresas } \\
\text { brasileiras que lançaram ADRs a partir } \\
\text { de 1992. }\end{array}$ & $\begin{array}{l}\text { As empresas que emitiram ADRs a partir de } 1992 \\
\text { aumentaram a visibilidade de suas ações, } \\
\text { obtiveram aumento da liquidez e do volume de } \\
\text { negócios e reduziram o risco de quase todos os } \\
\text { papéis. }\end{array}$ \\
\hline $\begin{array}{l}\text { Costa (2005) e Costa e Lopes } \\
\text { (2007) }\end{array}$ & $\begin{array}{l}\text { Avaliar a relevância das informações } \\
\text { disponibilizadas ao mercado por } \\
\text { empresas brasileiras com ADRs } \\
\text { negociados na NYSE, bem com a } \\
\text { importância dos ajustes efetuados no } \\
\text { lucro e no patrimônio líquido das } \\
\text { empresas brasileiras. }\end{array}$ & $\begin{array}{l}\text { As informações elaboradas segundo os princípios } \\
\text { de contabilidade, geralmente, aceitos no Brasil } \\
\text { são relevantes; no entanto as informações em US } \\
\text { GAAP disponibilizadas por essas empresas, em } \\
\text { junho de cada ano, possuem menor ou igual } \\
\text { relevância do que as divulgadas em abril. Os } \\
\text { ajustes aos US-GAAP efetuados ao patrimônio } \\
\text { líquido refletem informações relevantes ao } \\
\text { mercado. }\end{array}$ \\
\hline Tukamoto (2004) & $\begin{array}{l}\text { Demonstrar evidências sobre o nível de } \\
\text { gerenciamento de resultados das } \\
\text { empresas brasileiras, por meio de testes } \\
\text { empíricos com duas amostras de } \\
\text { empresas: as empresas brasileiras } \\
\text { registradas na Bovespa emissoras de } \\
\text { ADR e as empresas não emissoras de } \\
\text { ADR. }\end{array}$ & $\begin{array}{l}\text { O nível de gerenciamento de resultados não } \\
\text { difere nas duas amostras, portanto, a estrutura de } \\
\text { governança não alterou o nível de gerenciamento } \\
\text { dos resultados. }\end{array}$ \\
\hline Nascimento (2006) & $\begin{array}{l}\text { Verificar a eficiência do conteúdo } \\
\text { informacional do resultado contábil em } \\
\text { US GAAP das empresas com ações } \\
\text { negociadas na NYSE, por meio da } \\
\text { análise do comportamento dos retornos } \\
\text { das açóes na Bovespa próximo à data de } \\
\text { depósito do Formulário 20-F na SEC e, } \\
\text { para isso, definiu duas categorias de } \\
\text { eventos: "boas notícias" e "más } \\
\text { notícias", classificadas de acordo com o } \\
\text { lucro anormal. }\end{array}$ & $\begin{array}{l}\text { o lucro ou prejuízo em US GAAP não impactam, } \\
\text { significativamente, o retorno das ações no } \\
\text { mercado acionário brasileiro. }\end{array}$ \\
\hline
\end{tabular}




\section{Apêndice B - Empresas que compõem as amostras}

Empresas que compõem a amostra do Novo Mercado

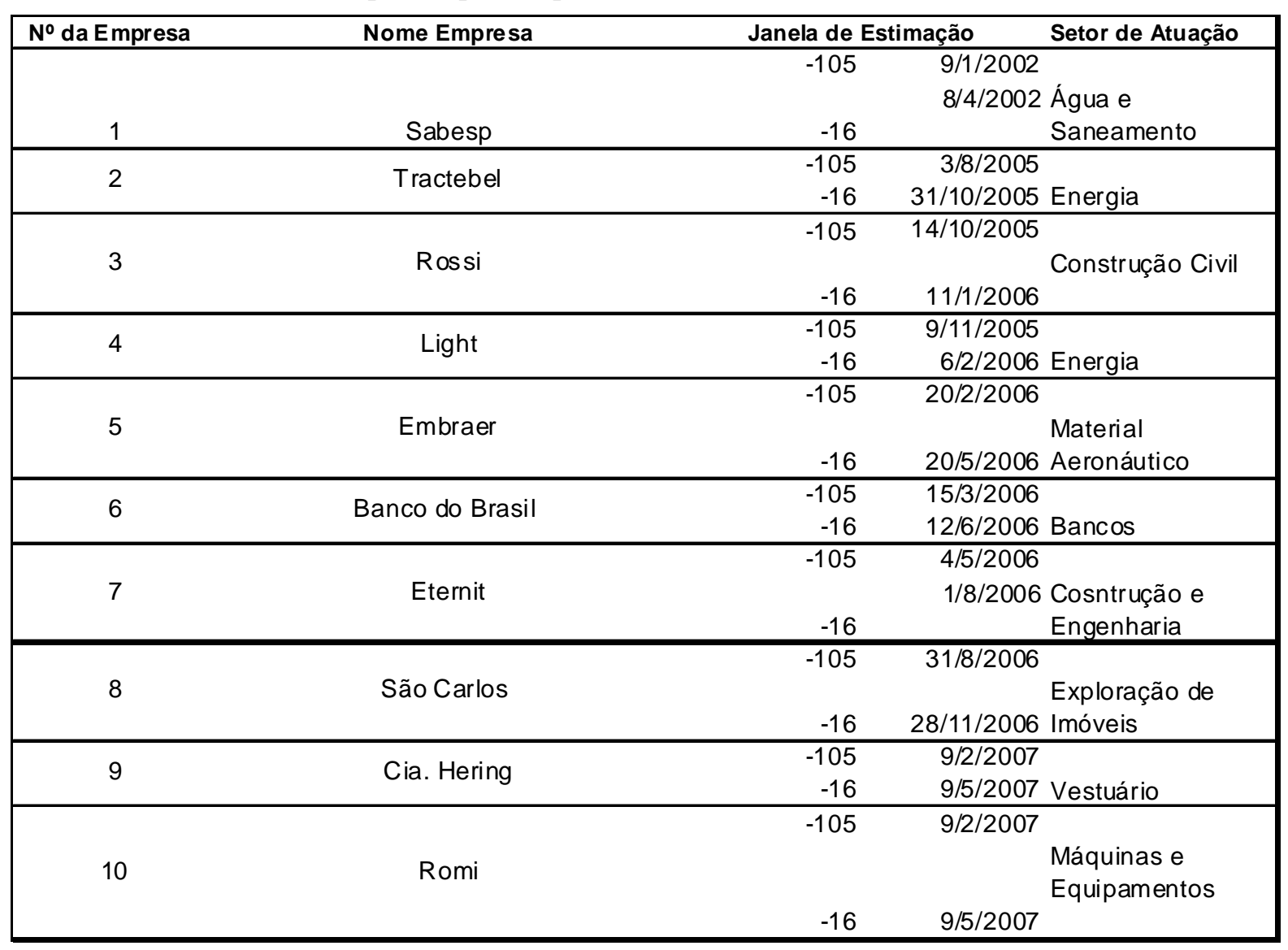


Empresas com ações ordinárias na BOVESPA que emitem ADRs na NYSE

\begin{tabular}{|c|c|c|c|c|}
\hline \multirow{3}{*}{$\begin{array}{c}\text { № da Empresa } \\
1\end{array}$} & \multirow{2}{*}{$\begin{array}{l}\text { Nome da Empresa } \\
\text { Vivo }\end{array}$} & \multicolumn{2}{|c|}{ Janela de Estimação } & \multirow{3}{*}{$\begin{array}{c}\text { Setor de Atuação } \\
\text { Telecomunicações }\end{array}$} \\
\hline & & -105 & $26 / 12 / 2005$ & \\
\hline & & -16 & $25 / 3 / 2006$ & \\
\hline \multirow[b]{2}{*}{2} & Tim Part. & -105 & $31 / 1 / 2006$ & Telecomunicações \\
\hline & & -16 & $30 / 4 / 2006$ & \\
\hline \multirow[b]{2}{*}{3} & CVRD & -105 & $9 / 2 / 2006$ & Minerais Metálicos \\
\hline & & -16 & $9 / 5 / 2006$ & \\
\hline \multirow[b]{2}{*}{4} & Gerdau & -105 & $6 / 3 / 2006$ & Siderurgia \\
\hline & & -16 & $3 / 6 / 2006$ & \\
\hline \multirow[b]{2}{*}{5} & Braskem & -105 & $6 / 3 / 2006$ & Petroquímica \\
\hline & & -16 & $3 / 6 / 2006$ & \\
\hline \multirow[b]{2}{*}{6} & Petrobrás & -105 & $15 / 3 / 2006$ & Petróleo \\
\hline & & -16 & $12 / 6 / 2006$ & \\
\hline \multirow[b]{2}{*}{7} & Bradesco & -105 & $17 / 3 / 2006$ & Bancos \\
\hline & & -16 & $14 / 6 / 2006$ & \\
\hline \multirow[b]{2}{*}{8} & Cemig & -105 & $17 / 3 / 2006$ & Energia \\
\hline & & -16 & $14 / 6 / 2006$ & \\
\hline \multirow[b]{2}{*}{9} & Embraer & -105 & $17 / 3 / 2006$ & Material Aeronáutico \\
\hline & & -16 & $14 / 6 / 2006$ & \\
\hline \multirow[b]{2}{*}{10} & Perdigão & -105 & $17 / 3 / 2006$ & Alimentos \\
\hline & & -16 & $14 / 6 / 2006$ & \\
\hline \multirow[b]{2}{*}{11} & Sadia & -105 & $17 / 3 / 2006$ & Alimentos \\
\hline & & -16 & $14 / 6 / 2006$ & \\
\hline \multirow{3}{*}{12} & Tele Norte & -105 & $17 / 3 / 2006$ & Telecomunicações \\
\hline & & -16 & $14 / 6 / 2006$ & \\
\hline & Unibanco & -105 & $17 / 3 / 2006$ & Bancos \\
\hline \multirow[t]{2}{*}{13} & & -16 & $14 / 6 / 2006$ & \\
\hline & Embratel & -105 & $17 / 3 / 2006$ & Telecomunicações \\
\hline \multirow[t]{2}{*}{14} & & -16 & $14 / 6 / 2006$ & \\
\hline & CSN & -105 & $20 / 3 / 2006$ & Siderurgia \\
\hline \multirow[t]{2}{*}{15} & & -16 & $17 / 6 / 2006$ & \\
\hline & Telesp & -105 & $28 / 12 / 2005$ & Telecomunicações \\
\hline \multirow[t]{2}{*}{16} & & -16 & $27 / 3 / 2006$ & \\
\hline & Aracruz & -105 & $6 / 3 / 2006$ & Papel e Celulose \\
\hline \multirow[t]{2}{*}{17} & & -16 & $3 / 6 / 2006$ & \\
\hline & Ambev & -105 & $10 / 5 / 2006$ & Bebidas \\
\hline \multirow[t]{2}{*}{18} & & -16 & $7 / 8 / 2006$ & \\
\hline & Banco Itaú & -105 & $23 / 2 / 2006$ & Bancos \\
\hline \multirow[t]{2}{*}{19} & & -16 & $23 / 5 / 2006$ & \\
\hline & Brasil Telecom Partic & -105 & $17 / 3 / 2006$ & Telecomunicações \\
\hline 20 & & -16 & $14 / 6 / 2006$ & \\
\hline & Brasil Telecom S/A & -105 & $17 / 3 / 2006$ & Telecomunicações \\
\hline 21 & & -16 & $14 / 6 / 2006$ & \\
\hline & Copel & -105 & $17 / 3 / 2006$ & Energia \\
\hline 22 & & -16 & $14 / 6 / 2006$ & \\
\hline & CPFL & -105 & $17 / 3 / 2006$ & Energia \\
\hline 23 & & -16 & $14 / 6 / 2006$ & \\
\hline & Sabesp & -105 & $17 / 3 / 2006$ & Água e Saneamento \\
\hline 24 & & -16 & $14 / 6 / 2006$ & \\
\hline
\end{tabular}


Empresas com ações preferenciais na BOVESPA que emitem $A D R$ na NYSE

\begin{tabular}{|c|c|c|c|c|}
\hline № da Empresa & Nome da Empresa & & Janela de & Setor de Atuação \\
\hline & & -105 & $5 / 12 / 2005$ & Aviação \\
\hline \multirow[t]{2}{*}{1} & Gol & -16 & $4 / 3 / 2006$ & \\
\hline & & -105 & $26 / 12 / 2005$ & Telecomunicações \\
\hline \multirow[t]{2}{*}{2} & Vivo & -16 & $25 / 3 / 2006$ & \\
\hline & & -105 & $20 / 1 / 2006$ & Distribuição Gás \\
\hline \multirow[t]{2}{*}{3} & Ultrapar & -16 & $19 / 4 / 2006$ & \\
\hline & & -105 & $31 / 1 / 2006$ & Telecomunicações \\
\hline \multirow[t]{2}{*}{4} & Tim Part. & -16 & $30 / 4 / 2006$ & \\
\hline & & -105 & $9 / 2 / 2006$ & Minerais Metálicos \\
\hline \multirow[t]{2}{*}{5} & CVRD & -16 & $9 / 5 / 2006$ & \\
\hline & & -105 & $6 / 3 / 2006$ & Siderurgia \\
\hline \multirow[t]{2}{*}{6} & Gerdau & -16 & $3 / 6 / 2006$ & \\
\hline & & -105 & $6 / 3 / 2006$ & Petroquímica \\
\hline \multirow[t]{2}{*}{7} & Braskem & -16 & $3 / 6 / 2006$ & \\
\hline & & -105 & $15 / 3 / 2006$ & Petróleo \\
\hline \multirow[t]{2}{*}{8} & Petrobrás & -16 & $12 / 6 / 2006$ & \\
\hline & & -105 & $17 / 3 / 2006$ & Bancos \\
\hline \multirow[t]{2}{*}{9} & Bradesco & -16 & $14 / 6 / 2006$ & \\
\hline & & -105 & $17 / 3 / 2006$ & Energia \\
\hline \multirow[t]{2}{*}{10} & Cemig & -16 & $14 / 6 / 2006$ & \\
\hline & & -105 & $17 / 3 / 2006$ & Alimentos \\
\hline \multirow[t]{2}{*}{11} & Sadia & -16 & $14 / 6 / 2006$ & \\
\hline & & -105 & $17 / 3 / 2006$ & Telecomunicações \\
\hline \multirow[t]{2}{*}{12} & Tele Norte & -16 & $14 / 6 / 2006$ & \\
\hline & & -105 & $17 / 3 / 2006$ & Bancos \\
\hline \multirow[t]{2}{*}{13} & Unibanco & -16 & $14 / 6 / 2006$ & \\
\hline & & -105 & $17 / 3 / 2006$ & Papel e Celulose \\
\hline \multirow[t]{2}{*}{14} & Votorantim & -16 & $14 / 6 / 2006$ & \\
\hline & & -105 & $17 / 3 / 2006$ & Telecomunicações \\
\hline \multirow[t]{2}{*}{15} & Embratel & -16 & $14 / 6 / 2006$ & \\
\hline & & -105 & $23 / 3 / 2006$ & Bancos \\
\hline \multirow[t]{2}{*}{16} & Itaú & -16 & $23 / 5 / 2006$ & \\
\hline & & -105 & $28 / 12 / 2005$ & Telecomunicações \\
\hline \multirow[t]{2}{*}{17} & Telesp & -16 & $27 / 3 / 2006$ & \\
\hline & & -105 & $6 / 3 / 2006$ & Papel e Celulose \\
\hline \multirow[t]{2}{*}{18} & Aracruz & -16 & $3 / 6 / 2006$ & \\
\hline & & -105 & $10 / 5 / 2006$ & Bebidas \\
\hline 19 & Ambev & -16 & $7 / 8 / 2006$ & \\
\hline \multirow{3}{*}{20} & & -105 & $17 / 3 / 2006$ & Telecomunicações \\
\hline & Brasil Telecom Participações & -16 & $14 / 6 / 2006$ & \\
\hline & & -105 & $17 / 3 / 2006$ & Telecomunicações \\
\hline \multirow[t]{2}{*}{21} & Brasil Telecom S/A & -16 & $14 / 6 / 2006$ & \\
\hline & & -105 & $17 / 3 / 2006$ & Energia \\
\hline 22 & Copel & -16 & $14 / 6 / 2006$ & \\
\hline
\end{tabular}




\section{Apêndice C - Resultados gráficos}

Comportamento do IPRA: Empresas no Novo Mercado e Empresas que emitem ADRs na NYSE

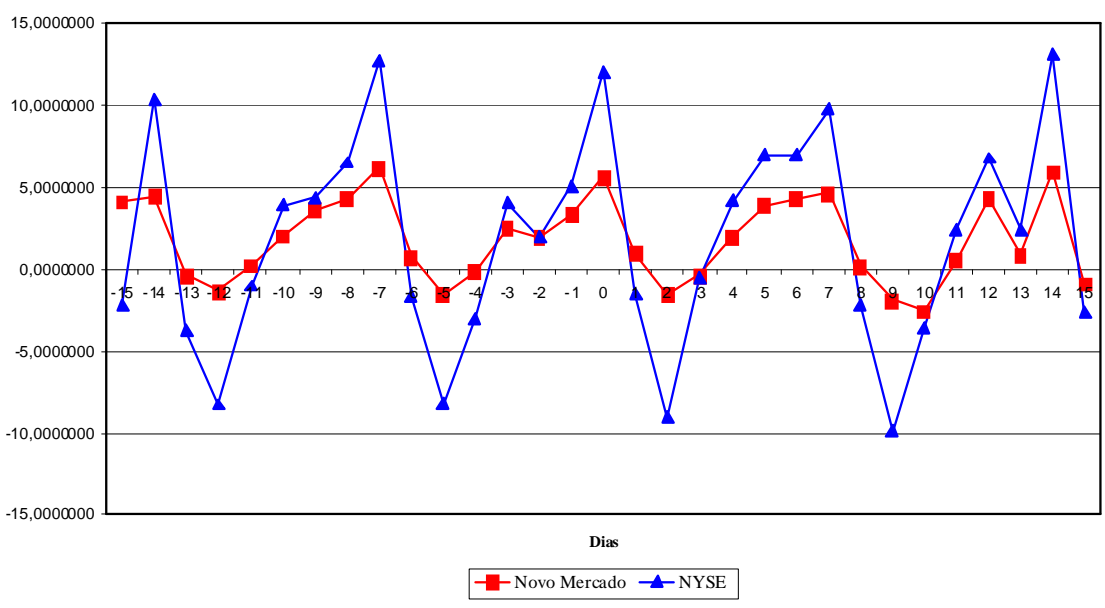

Comportamento do IPRA: A ções ON e PN de empresas que emitem ADRs na NYSE

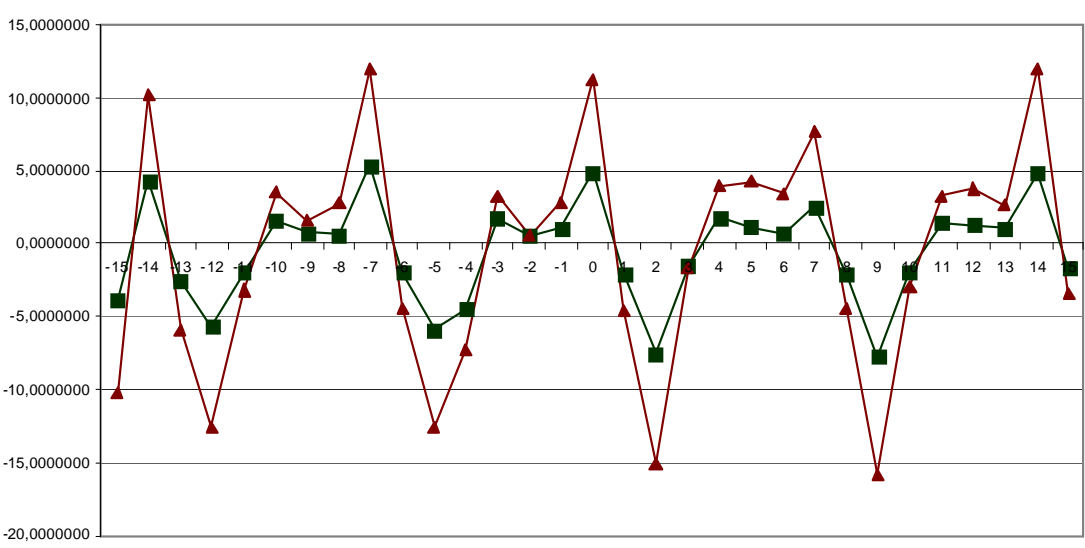

$-\mathrm{PN}-\mathrm{ON}$

Comportamento Líquidez Média - Novo Mercado

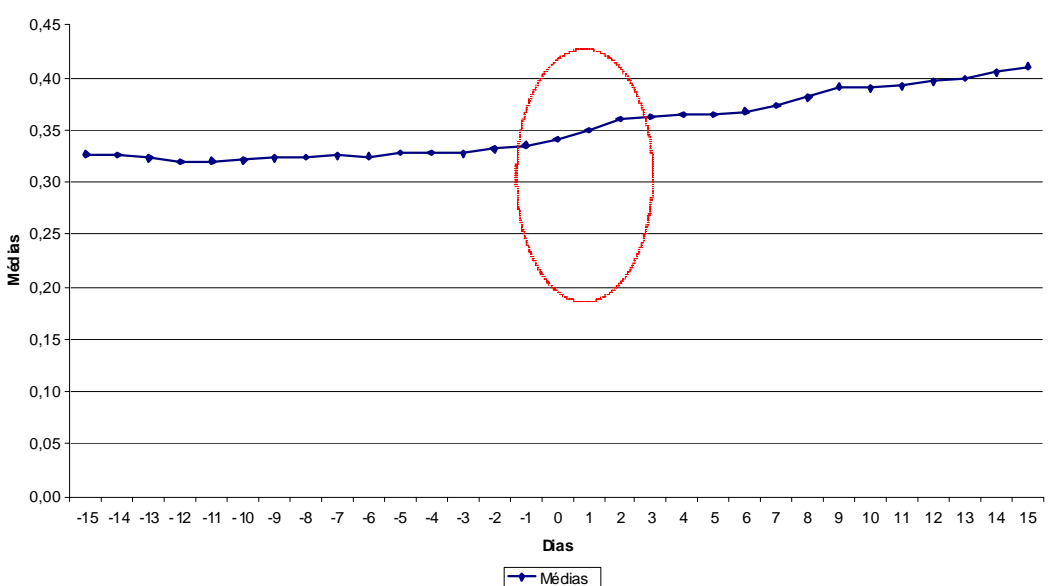




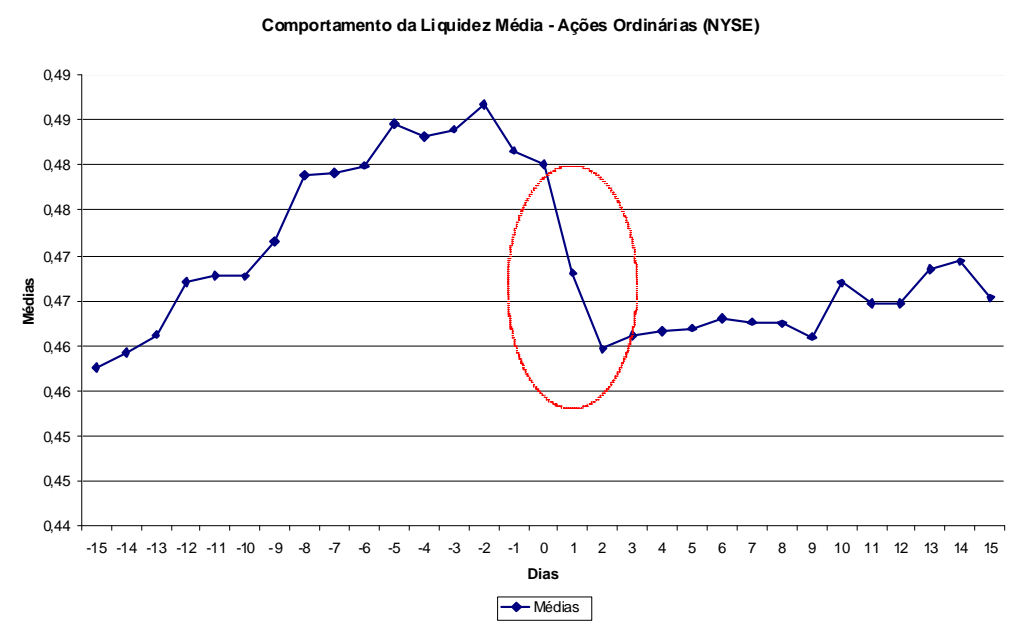

Comportamento da Liquidez Média - Ações Preferencias (NYSE)

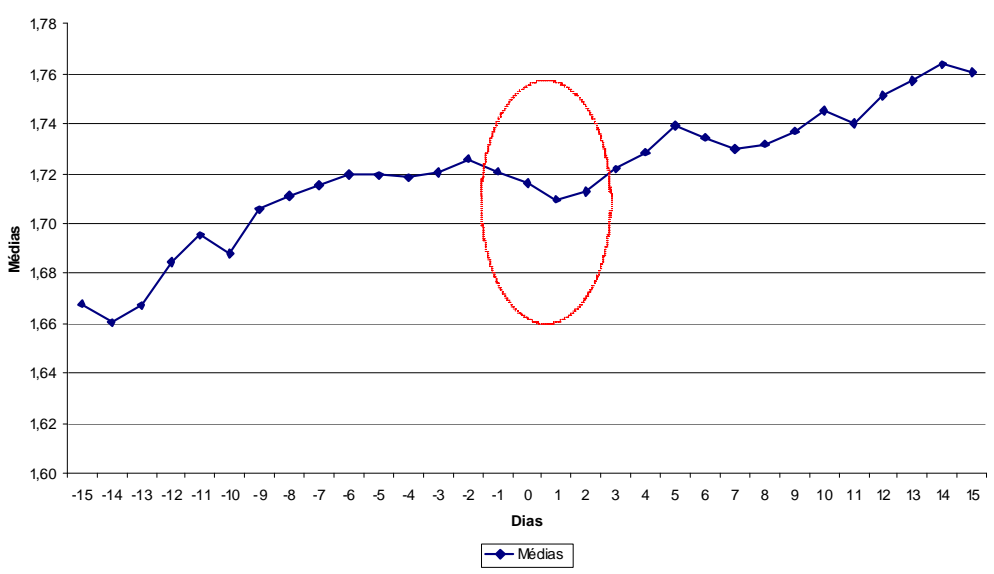

